\title{
Ingestion of microplastics and occurrence of parasite association in Mediterranean anchovy and sardine
}

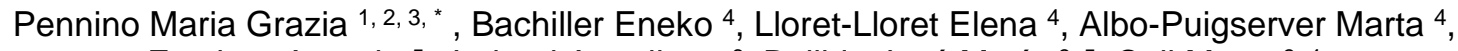 \\ Esteban Antonio ${ }^{5}$, Jadaud Angelique ${ }^{6}$, Bellido José María ${ }^{3,5}$, Coll Marta ${ }^{3,4}$
}

1 Instituto Español de Oceanografía, Centro Oceanográfico de Vigo, Subida a Radio Faro, 50-52, 36390

Vigo, Pontevedra, Spain

2 Fishing Ecology Management and Economics (FEME), Universidade Federal do Rio Grande do Norte

- UFRN, Depto. de Ecologia, Natal, RN, Brazil

${ }^{3}$ Statistical Modeling Ecology Group (SMEG), Departament d'Estadística i Investigació Operativa, Universitat de València, C/Dr. Moliner 50, Burjassot 46100, Valencia, Spain

${ }^{4}$ Institut de Ciències del Mar (CMIMA-CSIC), P. Marítim de la Barceloneta, 37-49, 08003 Barcelona, Spain

5 Instituto Español de Oceanografía, Centro Oceanográfico de Murcia, C/Varadero 1, San Pedro del Pinatar, 30740 Murcia, Spain

${ }^{6}$ MARBEC, Ifremer, Univ. Montpellier, CNRS, IRD, Bd Jean Monnet B.P. 171, 34203 Sète Cedex, France

* Corresponding author : Maria Grazia Pennino, email address : grazia.pennino@ieo.es

\begin{abstract}
:
We quantified the incidence of microplastics in the gut contents of the European sardine (Sardina pilchardus) and anchovy (Engraulis encrasicolus) in the Northwestern Mediterranean Sea and tested which variables influence this abundance, including the prevalence of parasites (i.e., trematoda larvae and nematodes). We detected a 58\% occurrence of microplastics ingestion in sardines and a $60 \%$ in anchovies. With respect to sardines, the individuals with lower body conditions were found to have the highest microplastics ingestion probabilities, whereas in anchovies such probabilities were observed in individuals with higher gonadosomatic indices and smaller size. The areas with the highest microplastics ingestion probabilities were the Gulf of Alicante for sardines and the Gulf of Lion - Ebro Delta for anchovies. Both species showed a positive relationship between parasites and microplastics ingestion. These results highlight that both parasitism and ingestion of microplastics are concerns for the health of marine stocks and human consumers.
\end{abstract}




\section{Graphical abstract}

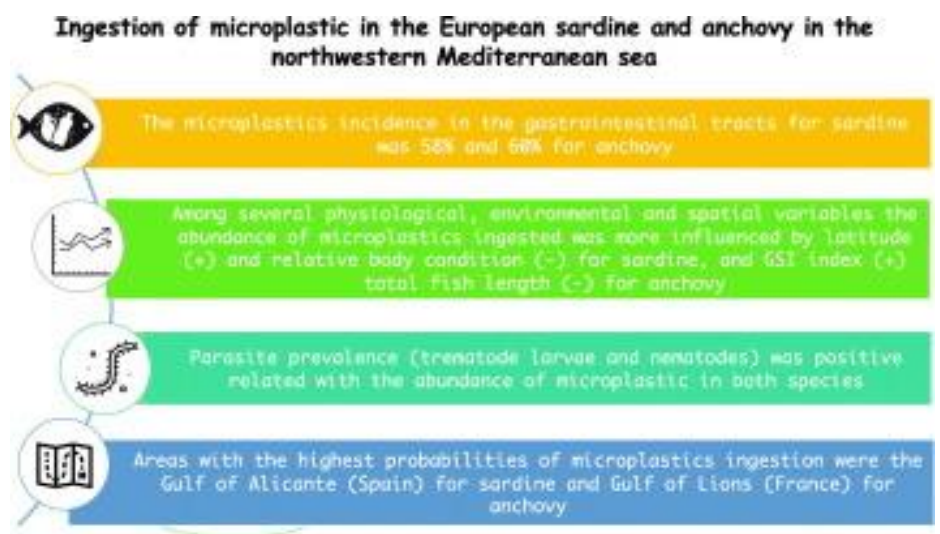

\section{Highlights}

Ingestion of microplastics was studied for Mediterranean anchovy and sardine. Occurrence of microplastics ingestion was $58 \%$ for sardines and $60 \%$ in anchovies. Microplastics abundance was influenced by latitude and body condition for sardines. For anchovy the main predictors were gonadosomatic index and total fish length. Parasite prevalence was positive related with microplastics abundance in both species.

Keywords : Bayesia, n Gut contents, Plastic ingestion, Fish parasites, Small pelagic fish 


\section{Introduction}

In recent decades, marine debris has become a serious threat to both the environment and biota. The importance of this problem is reflected in the implementation of descriptor 10 of the "Marine Strategy Framework Directive (MSFD)" of the EU, which monitors marine litter for a "Good Environmental Status (GES)" (European Parliament and Council of the European Union, 2008). Among the different types of marine litter, plastic pollution is of particular concern (Bergmann et al., 2015).

In terms of plastic pollution, the Mediterranean Sea is one of the most affected areas in the world, probably related to its natural environment, oceanographic regimes and the high level of anthropogenic activities in surrounding areas (Anastasopoulou et al., 2013; Cozar et al., 2015; de Haan et al., 2019; Deudero and Alomar, 2015; Filgueiras et al., 2019; García-Rivera et al., 2015; 2018; Ioakeimidis et al., 2014; Katsanevakis and Katsarou, 2004; Spedicato et al., 2020; Ramirez-Llodra et al., 2013). Studies carried out in the Mediterranean basin have reported up to 890,000 plastic items per $\mathrm{km}^{2}$; the majority of which are microplastics (diameter $<5 \mathrm{~mm}$ ) (Eriksen et al., 2014).

Recent studies have shown that pelagic and benthic fish ingest microplastics (Lusher et al., 2013; Lusher et al., 2017; Neves et al., 2015; Romeo et al., 2015) and that this could potentially cause mortality, reduce feeding activity, inhibit growth and development, disrupt endocrine, cause energy disorder, reduce immunity, and lead to neurotransmission dysfunction and even genotoxicity (Avio et al., 2015; Rochman et al., 2014; Wright et al., 2013). The physiological effects of microplastics ingestion have already been detected in different marine species, both field collected and treated laboratory experiments, including inflammation and lipid accumulation in the liver, neurotoxic effects and energy related changes, as well as oxidative stress induction (Barboza et al. 2018; Jeong et al., 2017; Yu et al., 2018). Furthermore, exposure to 
chemical pollutants associated to plastic particles has become a major concern, especially given that chemical bioaccumulation in fish can reach human consumption, with the effects still poorly understood (Teuten et al., 2009). Similarly, not much is known about the influence of microplastics retention on other substances present in fish gastrointestinal tracts, such as parasites, since they could potentially increase the surface area for adhesion and retention (Hernandez-Milian et al., 2019), weaker an individual's body conditions, and increase the probability of ingesting anthropogenic particles. Indeed, parasitism is another source of concern for marine stock health and human consumption safety (Casadevall et al., 2016). Healthier fish stocks could therefore be considered more resistant to parasite infections and plastic ingestion.

Among small pelagic fish species, Sardina pilchardus (European sardine, Walbaum, 1792) and Engraulis encrasicolus (European anchovy, Linnaeus, 1758) are the most commercialized fish in the northwestern Mediterranean Sea and represented up to $39 \%$ of the total catches in the region between 2014 and 2016 (FAO, 2018). These species have been shown to play an important role in the transfer of energy from lower to higher trophic level organisms (Albo-Puigserver et al., 2016; Coll et al., 2008; Palomera et al., 2007). Historically, they have shown an important bulk of biomass and production and played a key ecosystem role given their strong coupling between both pelagic and demersal environments, where they are important prey for pelagic predators, such as tunas (Navarro et al., 2017), cetaceans (Gómez-Campos et al., 2011), pelagic seabirds (Navarro et al., 2009) and demersal predators (Mellon-Duval et al., 2017). Additionally, they are widely distributed throughout the entire northwestern Mediterranean continental shelf (Giannoulaki et al., 2011; Giannoulaki et al., 2013) and have a particular feeding strategy that combines both filter and particulate feeding activities (Borme et al. 2009; Costalago et al. 2012; Plounevez and Champalbert, 2000; Nikolioudakis et al. 2014). All these 
characteristics make S. pilchardus (hereafter sardine) and E. encrasicolus, (hereafter anchovy) key candidates to assess exposure to microplastics, with possible public health concerns of microplastic ingestion (Smith et al., 2018).

Within this context, this study aims to (1) quantify the incidence of microplastics in the gut contents of these two commercial fish in a latitudinal gradient of the northwestern Mediterranean Sea; (2) investigate the implications of parasite prevalence in the accumulation of microplastics; (3) investigate the relationship between microplastic abundance and physiological, environmental and spatial factors; and (4) create spatially explicit predictions of the plastic levels ingested by species across a given landscape (hereafter plasticscapes).

\section{Material and methods}

\section{Data collection and study area}

Sardine and anchovy samples were collected as part of the EU-funded MEDIterranean Trawl Survey (MEDITS) carried out between the spring and early summer (April to June) of 2018. According to Bertrand et al., (2002), the MEDITS survey uses a stratified sampling design, with standardized trawls based on depths ( 5 bathymetric strata: 10 to 50,51 to 100,101 to 200,201 to 500 and 501 to $700 \mathrm{~m}$ ) and Geographical Sub-Areas (GSA). This study concerns the trawlable grounds of GSA 06 (Northern Spain) and 07 (Gulf of Lions), which borders the northwestern Mediterranean coast (Figure 1).

For each station both the geographical location (latitude and longitude) and the bathymetry (in meters) were recorded during the survey.

\section{Sample processing}


All individuals were immediately frozen after capture and stored at $-20^{\circ} \mathrm{C}$. In the laboratory, the samples were thawed at room temperature and morphological measurements were taken: total length $(\mathrm{cm})$, body weight $(\mathrm{g})$, sex $($ female $=\mathrm{F}$, male $=\mathrm{M}$, indetermined $=\mathrm{I}$ ), stage $($ adult $=\mathrm{A}$, juvenile $=\mathrm{J}$, with sardine juveniles considered to be $<11 \mathrm{~cm}$ and anchovy juveniles $<13 \mathrm{~cm}$, respectively (Palomera et al., 2003; Silva et al., 2006) and sexual maturity (inactive $=$ immature/resting, maturing, or active $=$ pre-laying, laying, spent). Stomachs were collected using stainless steel scissors and tweezers. To extract the stomach, the sample was cut from the top of the oesophagus to the pyloric caeca and preserved in pure ethanol $96^{\circ}$ (PanReac, UN1170 v/v).

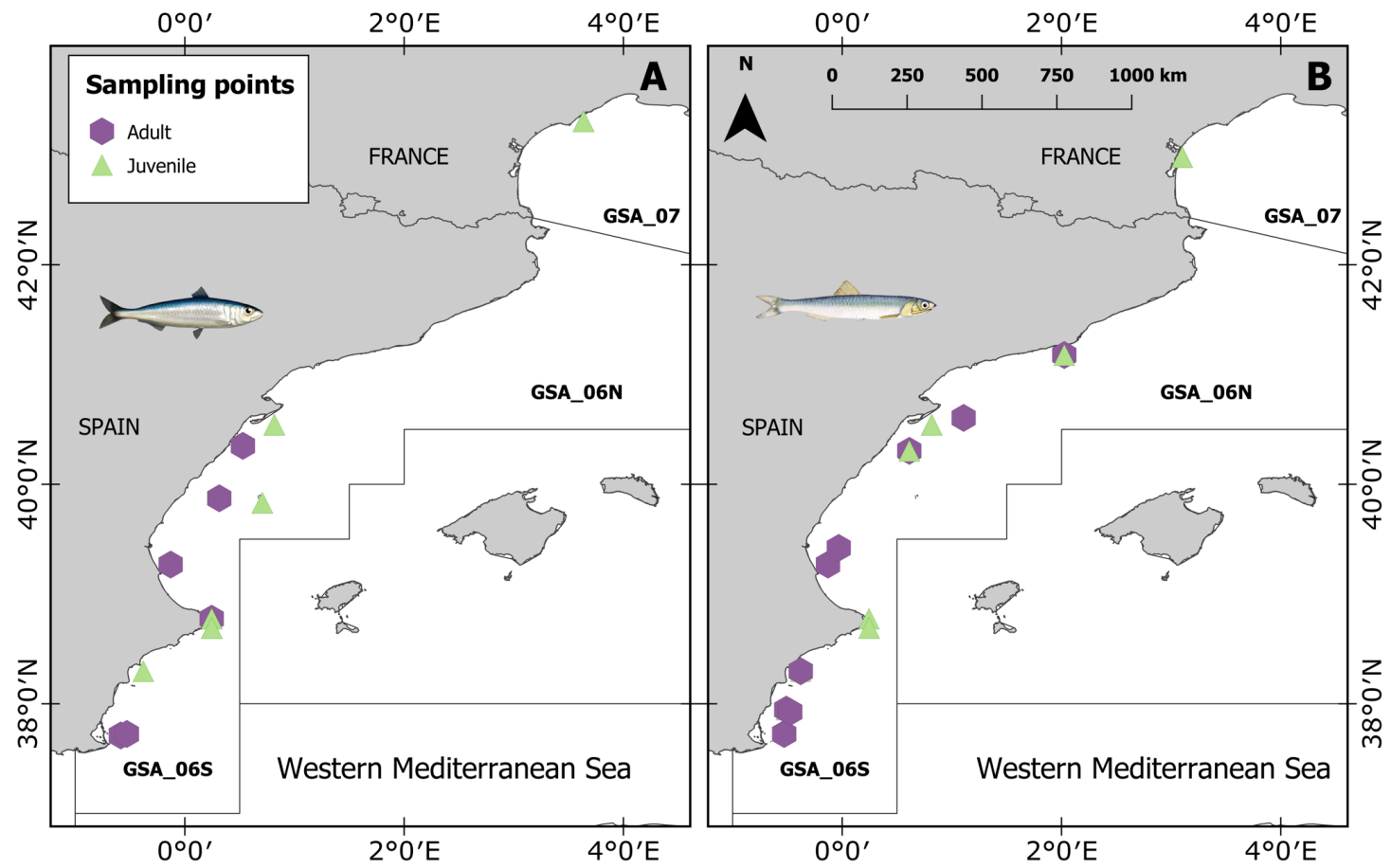

Figure 1: Map of the study area with sampling locations where European sardine (A) and anchovy (B) individuals (adults and juveniles) were caught. The geographical subareas are delimited by lines, with GSA 07 corresponding to the Gulf of Lions and GSA 06 subdivided into two areas: GSA 06N in the north and GSA 06S in the south.

We calculated the gonadosomatic index, $G S I=(W G / W T) * 100$, where $W G$ is the wet weight of the gonad and $W T$ is the total body weight of the individual minus the gonad weight. GSI is used as a measure of reproductive investment. In addition, we used the 
relative condition index $\left(\mathrm{K}_{\mathrm{n}}\right)(\mathrm{Le}$ Cren, 1951) as a proxy for both somatic condition and an indicator of length independent morphometric. The $\mathrm{K}_{\mathrm{n}}$ index is widely used to analyze species with allometric growth patterns and its use has been validated for sardine and anchovy (Brosset et al., 2015). The relative condition factor was computed as: $K_{n}=W / W_{r}$, where $W$ is the mass of an individual and $W_{r}$ is the theoretical mass of an individual given a total length TL. $W_{r}$ was predicted by the length-weight relationship calculated from all individuals sampled, $\mathrm{W}_{\mathrm{r}}=\alpha \mathrm{TL}^{\beta}$, where $W_{\mathrm{r}}=$ total weight minus the gonad weight $(\mathrm{g})$, $T L=$ total fish length $(\mathrm{cm})$ and $\alpha$ and $\beta$ are the regression coefficients. By definition the values of the relative condition factor $\left(\mathrm{K}_{\mathrm{n}}\right)$ are distributed around 1 . Values above 1 are individuals in a better condition than a standard individual. Values below 1 are individuals in a worse condition than a standard individual of the same size.

Gut contents of sardine and anchovy were extracted from the stomachs under a stereomicroscope (model NIKON SMZ 1270). Extraction and analysis of gut contents were carried out using pure ethanol 96 (PanReac, UN1170 v/v) and always using glassware (i.e., vials, petri plate and cover). Gut contents were characterized individually, and no sub-sampling was carried out. Only the material contained in the stomachs was considered, discarding the contents of the intestine and the oesophagus in order to exclude bias from different rates of digestion and cod-end feeding, respectively (Hyslop, 1980). Additionally, by excluding oesophagus contents it avoids counting potential microplastic debris ingestion (Welden and Cowie, 2016) just prior to fish collection (e.g., contamination of micro-pieces of paint from the vessel or fishing gear that could have detached and become concentrated into the cod-end of the trawl net and been ingested by the fish). During the gut content processing plastics were measured with an ocular micrometer in the microscope in order to classify them as either microplastic (length and/or diameter $<5 \mathrm{~mm}$ ) or mesoplastic (length and/or diameter $>5 \mathrm{~mm}$ ) (Baker and 
Bamford, 2009). Furthermore, all materials were counted and sub-classified by shape into two main groups: 'fibres' (i.e., fibres, including polyester-made clothes and artificial cellulose remains (Suaria et al. 2020), as well as pieces of fishing-lines, the latter clearly identified due to their low degree of degradation, diameter and shape, as well as their hardness and inflexibility) and 'other' (mainly plastic fragments, such as plates from paints and plastic-bag remains). All 'other' particles were micro-plastics (i.e. $<5 \mathrm{~mm}$ ). The laboratory practice followed the standard procedures to avoid contamination during sample processing (Nadal et al. 2016; Lusher et al. 2017; Woodall et al., 2014). Accordingly, microscope analysis was conducted in a 'clean room' (i.e., a non-ventilated room with low foot traffic and embargoed to non-essential personnel, Lusher et al. 2017), with researchers wearing a white $100 \%$ cotton laboratory coat and latex gloves, and an air extractor placed $20-30 \mathrm{~cm}$ above the petri plate with the gut samples to avoid ethanol inhalation and fiber contamination from clothes into the samples. Glassware, bench, microscope slide and dissection equipment (i.e., stainless-steel scissors, scalpel and lancet) were rinsed with pure ethanol prior to each gut content analysis (Cole et al. 2014). Counted plastics, often attached to gut content remains (i.e., other zooplanktonic organisms and/or digested remains), were manually separated from gut contents. Similarly, 'clean fibers' (i.e., fibers without any attached piece of gut content remains) were considered to be plastic from air contamination during the sample processing and were, therefore, excluded from analysis (Rodriguez-Romeu et al., 2020). This assumption could result in partial underestimation of plastic ingestion given that clean fibers ingested by fish right before they were caught were preserved and unaltered until the microscope analysis; however, at the same time, it excludes plastic overestimation from contamination by air-pollution during gut content analyses. 
On the other hand, all identifiable parasites were counted and classified to the lowest possible taxonomic group. Broken parts of organisms were excluded from the analysis. Two parasite groups were identified: trematoda larvae and nematodes.

The feeding intensity was assessed by using the Stomach Filling Degree (SFD) as a proxy, which was defined as the sum of weights of all the prey identified in a stomach (mg) divided by the total length of the fish $(\mathrm{mm})$. This approach excludes the effect of the fish size and is considered to be a useful estimator of feeding intensity (e.g., Bachiller and Irigoien, 2013; 2015; Bachiller et al., 2016).

\section{Statistical analysis}

The abundance of microplastics ingested by individuals from each species was analyzed using a statistical modelling approach that included the following variables: total fish length, body weight, sex, stage, sexual maturity, $\mathrm{K}_{\mathrm{n}}$, GSI index, SFD, depth, latitude, longitude, and the number of total parasites found in each stomach (considering trematoda larvae and nematodes together). The remaining source of variation on the abundance of ingested microplastics could potentially be caused by different sources of intrinsic variability from individual fish or the area. Consequently, we included two random effects in the models: "individual effect" and "area" (GSA 07, GSA 06 north and GSA 06 south).

For each species a Bayesian Generalized Linear Mixed Model (B-GLMM) with a negative binomial error was implemented to account for the overdispersion of the response variables.

Standardized data exploration techniques were used to identify any outliers and possible correlation and collinearity between the explicative variables (Zuur et al., 2010). For both species, longitude and latitude, as well as total fish length and body weight, were 
found to be highly correlated and have a high degree of collinearity among them (Pearson correlation $\mathrm{r}=>0.80$ and VIF $>3$ ) (Fig. S1 and Fig. S2). Thus, these variables were included in the models separately.

To better interpret both the direction (positive or negative) and magnitudes (effect sizes) of the parameter estimates in relation to the others, after the explanatory analysis the explanatory variables were standardized, i.e., difference from the mean divided by the corresponding standard deviation (Gelman, 2008; Hereford et al., 2004).

Following the Bayesian approach, a non-informative zero-mean Gaussian prior distribution was assigned to the fixed effects with a variance of 100 (Muñoz et al., 2013), given that no prior information on the modeling parameters was available.

In order to compare the goodness-of-fit for each model, two different measures were computed: (1) the Watanabe-Akaike information criterion (WAIC) (Watanabe, 2010) and (2) the log-conditional predictive ordinates (LCPO) (Roos and Held, 2011). Specifically, WAIC was used as a measure of goodness-of-fit, and LCPO was used as a predictive quality indicator. Lower WAIC and LCPO values indicate better models.

For each estimated parameter of the final selected model the probability (Pr) that they were different that 0 was computed $(\operatorname{Pr}>$ or $<0)$ using the Bayes theorem property. B-GLMMs were performed using the R-INLA package (Rue et al., 2009).

Finally, using the INLA Stochastic Partial Differential Equations (SPDE) approach (Lindgren et al., 2011), the predicted distributions of plastic abundance, or plasticscapes, by species, were generated. Models were specified as follows:

$$
\mathrm{Y}_{\mathrm{i}} \sim \alpha+\mathrm{f}\left(\mathrm{W}_{\mathrm{i}}\right)+\varepsilon_{\mathrm{i}}
$$

where $\mathrm{Y}_{\mathrm{i}}$ is the microplastic abundance at location $i$ that follows a negative binomial distribution, $\alpha$ is the intercept of the model, $\mathrm{W}_{\mathrm{i}}$ represents the smooth spatial effect that links each microplastic observation with a spatial location, and $\varepsilon_{\mathrm{i}}$ contains the 
independently distributed residuals. For the spatial component, a multivariate Gaussian distribution with a zero mean and a Matérn correlation matrix was assumed (Muñoz et al., 2013). Plastiscapes abundance by species were then generated to predict the response variable for the entire study area using linear interpolation via a Bayesian kriging (St. John Glew et al., 2018).

\section{Results}

\section{European sardine}

A total of 104 sardine individuals were analyzed, and microplastic items were found in 60 individuals (58\%) (Table 1). Mesoplastic items were found in only a single adult in the GSA06 south (Table 1). Microplastics were found to be ingested in all the areas, as follows: in 21 of the 40 individuals in GSA07 (52.5\%), 16 of the 30 individuals in GSA06 north (53\%) and 23 of the 34 individuals in GSA06 south (68\%) (Table 1). Considering all plastic types and both juvenile and adult anchovies together, on average between 1 and 2 items were ingested. Almost all the microplastic items were classified as fibres (i.e., pieces of fishing-lines, fibres of polyester-made clothes), whereas other items (mainly plates from paints or plastic-bag remains) (Table 1) were only found in the stomachs of a single juvenile sardine in GSA06 south.

Parasites were found in almost all the areas in both juveniles and adults with a prevalence of trematoda larvae. GSA06 north was the area with the highest proportion of parasites in gut contents, with parasites found in $66.7 \%$ of juveniles and $86.7 \%$ of adults (Table 1).

The final B-GLMM examining the abundance of ingested microplastics in sardines included latitude, quantity of parasites found in the stomach, the $\mathrm{K}_{\mathrm{n}}$ relative condition factor and the area random effect. The variables individual fish random effect, 
total fish length, body weight, sex, stage, sexual maturity, GSI index, SFD, depth and longitude were not relevant (Table S1).

There was a probability of $87 \%$ that in higher latitudes the abundance of ingested microplastics is lower for this species (Figure 2). In addition, results showed an $89 \%$ probability that fish with a higher abundance of parasites have a higher abundance of ingested microplastics (Figure 2). The $\mathrm{K}_{\mathrm{n}}$ was revealed to have a negative relationship with the quantity of ingested microplastics, with a probability of $77 \%$ that individuals with lower $K_{n}$ values have a greater abundance of microplastics (Figure 2). Such latitudinal differences in the abundance of the ingested microplastics were also reflected by the relevance of the random effect area.
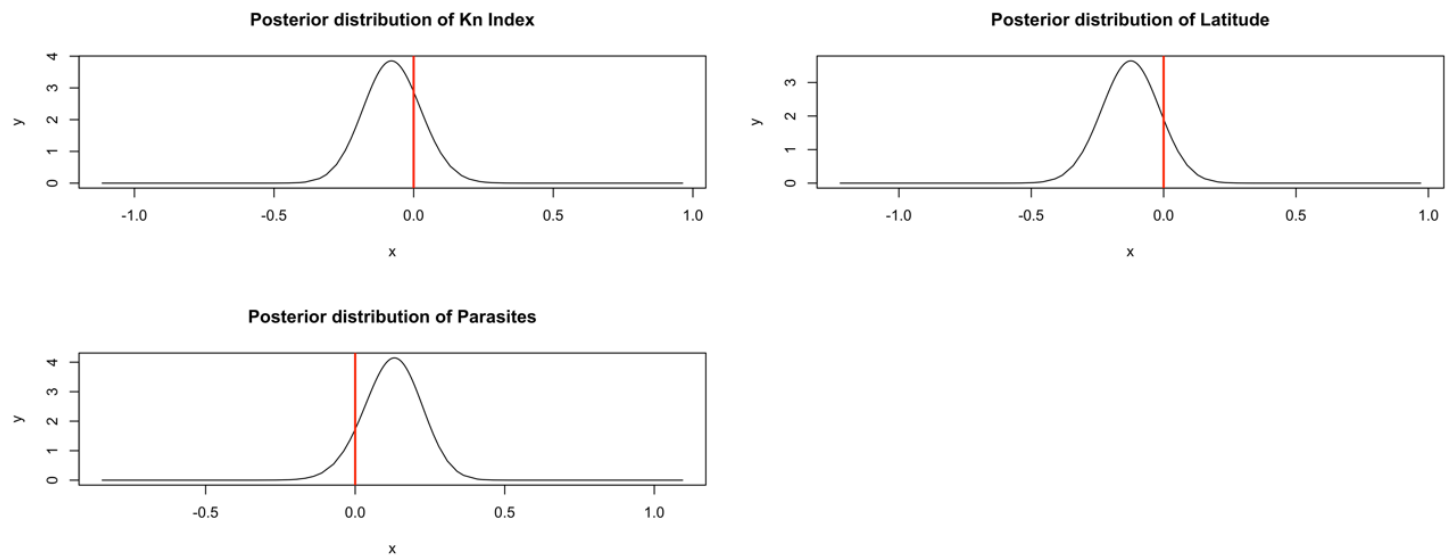

Figure 2: Posterior marginal distributions of the relevant continuous variables for the final European sardine B-GLMM for abundance of ingested microplastics: $K_{n}$ relative condition factor (top left), latitude (top right) and abundance of parasites found in the stomachs (bottom left). The posteriori marginal distributions are the probability densities (y-axis) for each estimated coefficient beta ( $x$-axis).

When the effect sizes of parameter estimates were compared, latitude was the most relevant factor (posterior mean $=-0.13$, IC 95\% $[-0.34,0.08]$ ), followed by the abundance of parasites (posterior mean $=0.12$, IC $95 \%[-0.07,0.30]$ ), and the $K_{n}$ relative condition factor $($ posterior mean $=-0.07$, IC 95\% $[-0.27,0.13])($ Figure 3$)$. 
Table 1: Descriptive summary of the sampled individuals and ingested plastic items found, by sample area (Area) and by ontogenetic stage (Stage). The number of sampled individuals (n), median relative condition factor $\left(\mathrm{K}_{\mathrm{n}}\right)$, percentage of stomachs with occurrence of plastics $(\%$ SC plastics), mean plastic abundance (i.e., mean number of plastic items per fish, N) found in the stomach content (and standard error SE) classified as Microfibre $(<5 \mathrm{~mm})$, Meso-fibre $(>5 \mathrm{~mm})$ and other type of plastic (Others, $<5 \mathrm{~mm})$. The parasite contents are reported as the percentage of stomachs with occurrence of parasites (\% SC parasites) and the mean number of parasites (N) per fish (and standard deviation, SE) that correspond to Trematoda larvae (trematoda lv.) and nematode parasites.

\begin{tabular}{|c|c|c|c|c|c|c|c|c|c|c|c|}
\hline \multirow[b]{2}{*}{ Area } & \multirow[b]{2}{*}{ Stage } & \multirow[b]{2}{*}{$\mathrm{n}$} & \multirow[b]{2}{*}{$\begin{array}{l}\text { Median length } \\
\text { (min-max; cm) }\end{array}$} & \multirow[b]{2}{*}{$\begin{array}{l}\text { Median } K_{n} \\
\text { (min-max) }\end{array}$} & \multicolumn{4}{|c|}{ Plastic pollution in diet } & \multicolumn{3}{|c|}{ Parasites in gut contents } \\
\hline & & & & & $\begin{array}{c}\% \text { SC } \\
\text { plastics }\end{array}$ & $\begin{array}{c}\text { Micro-fibre } \\
\mathrm{N}( \pm \mathrm{SE})\end{array}$ & $\begin{array}{c}\text { Others } \\
\mathrm{N}( \pm \mathrm{SE})\end{array}$ & $\begin{array}{c}\text { Meso-fibre } \\
N( \pm \text { SE })\end{array}$ & $\begin{array}{c}\% \mathrm{SC} \\
\text { parasites }\end{array}$ & $\begin{array}{c}\text { Trematoda lv. } \\
\mathrm{N}( \pm \mathrm{SE})\end{array}$ & $\begin{array}{c}\text { Nematodes } \\
N( \pm \text { SE })\end{array}$ \\
\hline \multicolumn{12}{|c|}{ Sardina pilchardus } \\
\hline \multirow{2}{*}{ GSA07 } & Juvenile & 40 & $11.15(9.6-12.8)$ & $1.02(0.85-1.11)$ & 52.5 & $1.52 \pm 0.18$ & 0 & 0 & 30.0 & $2 \pm 0.49$ & $0.25 \pm 0.18$ \\
\hline & Adult & - & - & - & & - & - & - & & - & - \\
\hline \multirow{2}{*}{$\begin{array}{l}\text { GSA06- } \\
\text { north }\end{array}$} & Juvenile & 15 & $9.0(7.8-10.2)$ & $0.96(0.80-1.06)$ & 60.0 & $1.33 \pm 0.17$ & 0 & 0 & 66.7 & $2.20 \pm 0.29$ & $0.10 \pm 0.10$ \\
\hline & Adult & 15 & $14.0(13.1-16.9)$ & $1.04(0.82-1.11)$ & 46.7 & $1.14 \pm 0.14$ & 0 & 0 & 86.7 & $1.92 \pm 0.24$ & $0.08 \pm 0.08$ \\
\hline \multirow{2}{*}{$\begin{array}{l}\text { GSA06- } \\
\text { south }\end{array}$} & Juvenile & 15 & $10.3(8.5-11.7)$ & $0.96(0.80-1.14)$ & 66.7 & $1.80 \pm 0.20$ & $0.10 \pm 0.10$ & 0 & 60.0 & $2.22 \pm 0.40$ & $0.33 \pm 0.24$ \\
\hline & Adult & 19 & $16.6(13.4-17.8)$ & $1.00(0.78-1.07)$ & 68.4 & $1.77 \pm 0.28$ & 0 & $0.08 \pm 0.08$ & 36.8 & $2.43 \pm 0.43$ & $0.29 \pm 0.18$ \\
\hline \multicolumn{12}{|c|}{ Engraulis encrasicolus } \\
\hline \multirow{2}{*}{ GSA07 } & Juvenile & 40 & $9.3(8.5-11.0)$ & $1.04(0.79-1.36)$ & 72.5 & $1.66 \pm 0.17$ & 0 & 0 & 75.0 & $2.40 \pm 0.37$ & 0 \\
\hline & Adult & - & - & - & - & - & - & - & - & - & - \\
\hline \multirow{2}{*}{$\begin{array}{l}\text { GSA06- } \\
\text { north }\end{array}$} & Juvenile & 15 & $9.6(8.9-10.6)$ & $0.99(0.69-1.25)$ & 73.3 & $1.55 \pm 0.31$ & 0 & 0 & 53.3 & $2.88 \pm 0.69$ & 0 \\
\hline & Adult & 20 & $12.7(10.9-14.8)$ & $0.98(0.75-1.56)$ & 60.0 & $1.67 \pm 0.33$ & $0.08 \pm 0.08$ & 0 & 45.0 & $3.89 \pm 2.28$ & 0 \\
\hline \multirow{2}{*}{$\begin{array}{l}\text { GSA06- } \\
\text { south }\end{array}$} & Juvenile & 6 & $10.0(9.2-10.8)$ & $0.84(0.76-0.98)$ & 50.0 & $2.00 \pm 0.58$ & $0.33 \pm 0.33$ & 0 & 16.7 & 1 & 0 \\
\hline & Adult & 22 & $14.0(13.1-16.2)$ & $1.12(0.72-1.70)$ & 31.8 & $1.86 \pm 0.46$ & 0 & 0 & 9.1 & $1.50 \pm 0.50$ & 0 \\
\hline
\end{tabular}




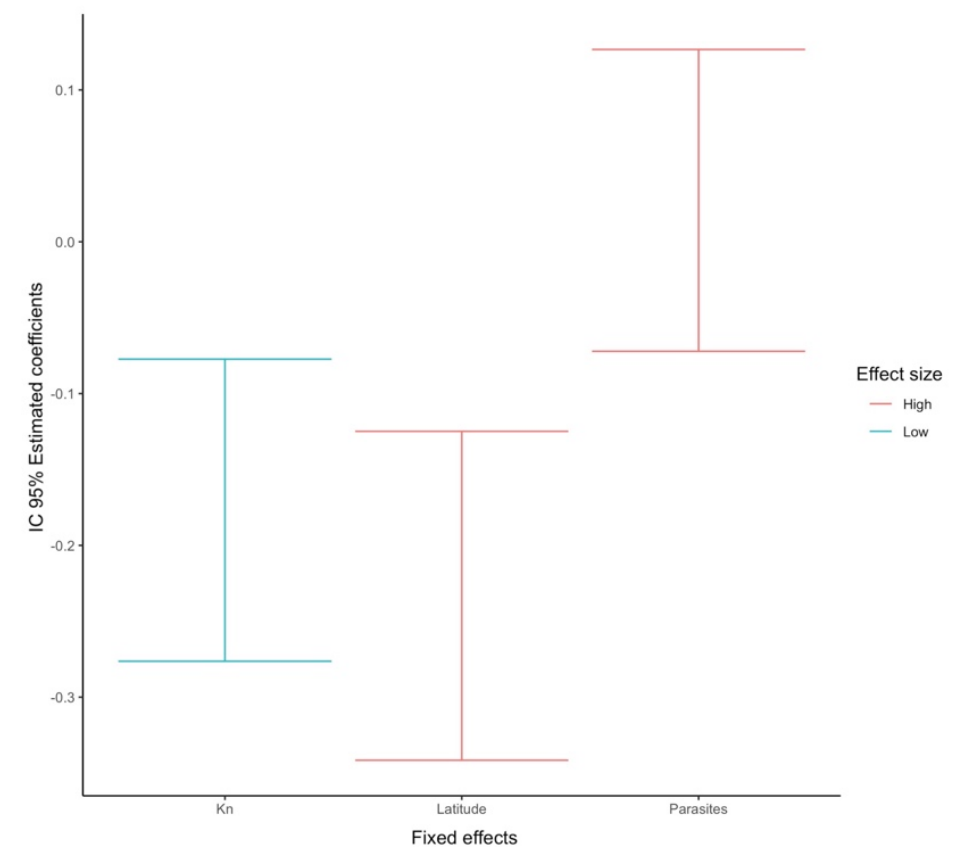

Figure 3: Credible Interval of 95\% (IC) of the parameter estimates for the fixed effects of the final European sardine B-GLMM for the abundance of ingested microplastics. $K_{n}$ : relative condition factor.

\section{European anchovy}

A total of 103 anchovy individuals were analyzed and microplastic items were found in 62 fishes (60\%) (Table 1). In GSA07, microplastics were found in 29 of the 40 individuals (72\%), whereas in GSA06 north, microplastics were found in 23 of the 25 individuals (65\%) and in GSA06 south in 10 of the 28 individuals (36\%) (Table 1). Considering all plastic types found in both juvenile and adult anchovies together, on average between 1 to 2 items were ingested. Mesoplastic items were not found in any stomachs of this species. Almost all the microplastic items were classified as fibres, and items classified as other were only found in 4 individuals in GSA06 (both south and north) (Table 1). For this species no nematodes were found, however trematoda larvae were present in almost all the areas with a prevalence among juveniles in the GSA07 of 75\% and in the GSA06 north of $53.3 \%$ (Table 1$)$. 
In the final B-GLMM model of the abundance of ingested microplastics in anchovies, the relevant variables were abundance of parasites found in the fish stomach, GSI index, total fish length and the area random effect. Depth, latitude, longitude, fish body weight, sex, stage, sexual maturity, $\mathrm{SFD}, \mathrm{K}_{\mathrm{n}}$ and the individual random effect were not relevant.

Results revealed a $94 \%$ probability of finding more abundance of microplastics when the abundance of parasites in the stomachs of anchovies is higher (Figure 4). Similarly, when the GSI index was higher there was an $89 \%$ probability of $89 \%$ of finding more abundance of microplastics (Figure 4). Conversely, results revealed a 99\% probability of a negative relationship between total fish length and ingested microplastic abundance, suggesting that smaller organisms ingest more microplastics (Figure 4).
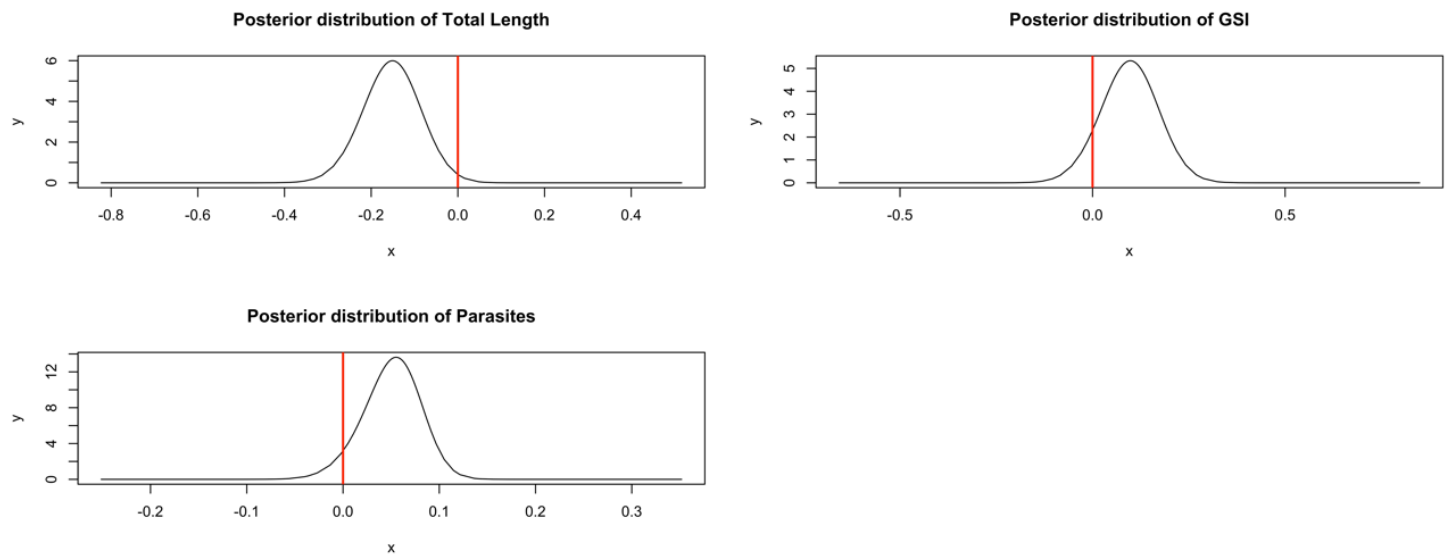

Figure 4: Posterior marginal distributions of the relevant continuous variables of the final European anchovy B-GLMM for abundance of ingested microplastics: latitude (left) and abundance of parasites found in the stomachs (right). The posteriori marginal distributions are the probability densities (y-axis) of each estimated beta coefficient ( $x$ axis).

Finally, the relevance of the area random effect highlighted that there is some intrinsic variability in the area that affects the abundance of microplastics ingested by individuals of this species. 
When the effect size of the estimated parameters where compared, results revealed that total fish length was the most relevant variable (posterior mean $=-0.15$, IC $95 \%[0.07$ $-0.15]$ ), followed by the GSI index (posterior mean $=0.09$, IC 95\% $[-0.05,0.24]$ ) and the abundance of ingested parasites (posterior mean $=0.05$, IC 95\% $[-0.01,0.10]$ ) (Figure 5).

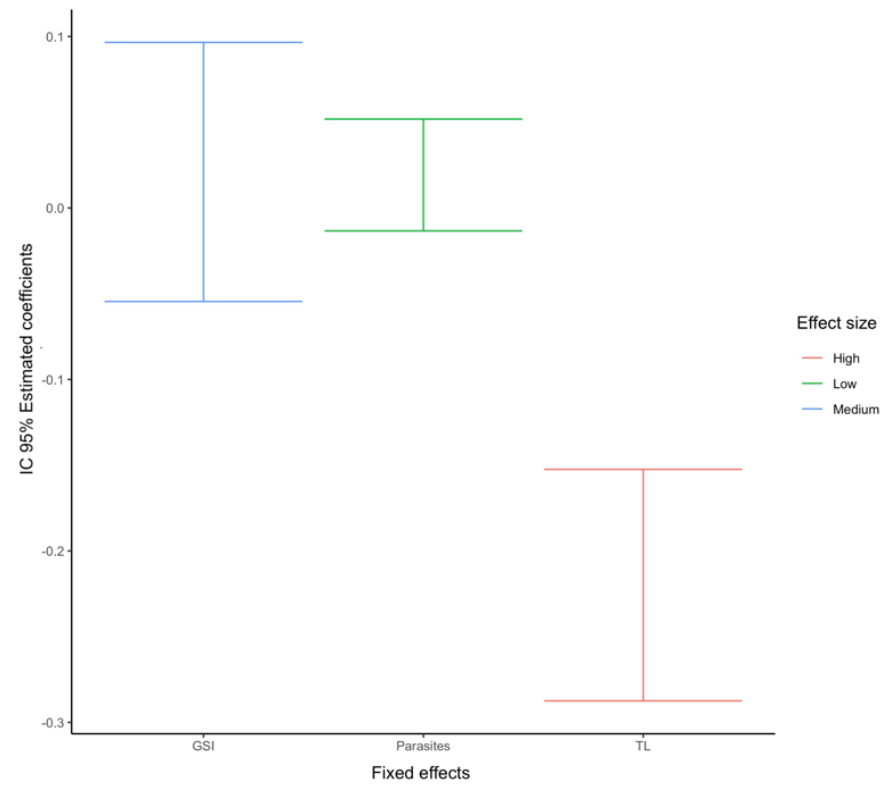

Figure 5: Credible Interval of 95\% (IC) of the parameter estimates for the fixed effects of the final European anchovy B-GLMM. GSI: gonadosomatic index, TL: total length.

\section{Plasticscapes}

Predicted plastic ingestion maps showed that the hot-spot areas of ingested plastics were different for the two species. In particular, sardine appeared to be more vulnerable to microplastic ingestion within the area of the Gulf of Alicante (GSA06 south, Figure 6A), whereas the ingestion of microplastics by anchovy seemed to be higher in the Gulf of Lion (GSA07), and the Ebro Delta (GSA06 north) continental shelves (Figure $6 \mathrm{~B})$. 


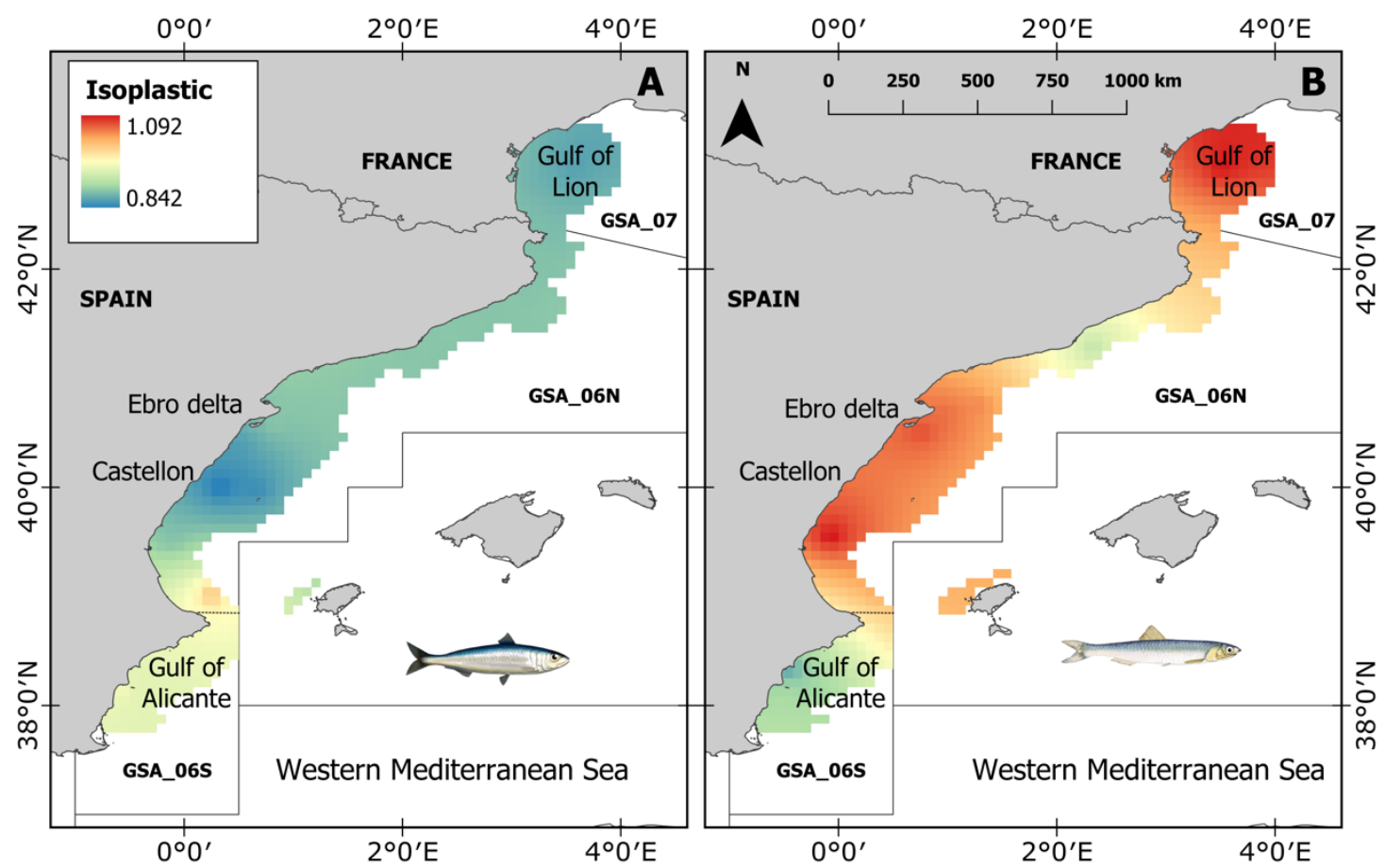

Figure 6: Plasticscapes of European sardine (A) and anchovy (B) obtained plotting the posterior mean of the spatial B-GLM by species.

\section{Discussion}

In this study we quantified the abundance of ingested microplastics for two commercial small pelagic species of the Western Mediterranean Sea, S. pilchardus and E. encrasicolus, and we tested which variables could influence this abundance, including the quantities of parasites found in each stomach of each species.

Overall, our findings indicate an ingestion of microplastic frequency of $58 \%$ for sardine and 60\% for anchovy in the northwestern Mediterranean Sea. Compa et al., (2018) showed lower frequencies (14.28 and $15.24 \%$ for sardine and anchovy, respectively) in the same area three years before, in 2015. This dissimilarity could be due to the fact that Compa et al. (2018) analyzed the whole gastrointestinal tract and/or to the nature of the sampling both in time and methods. Indeed, Compa et al (2018) sampled fish in July 2015 with a pelagic gear which fishes in the surface strata of the water column, while in this study individuals were collected in May 2018 using a demersal gear which fishes close 
to the seabed. These results could suggest that the distribution of microplastics abundance in the water column is heterogeneous (Choy et al., 2019) and that it is higher at the bottom near the seabed. Further research is needed regarding this issue, based on specific campaigns to monitor conditions at different depths in the water column and at different times of the day and the year. However, abundance of ingested microplastic in this study was not related to depth according to the B-GLMM.

Anchovies caught in the Western Mediterranean Sea had lower frequencies of ingested microplastics than those caught in the Eastern and Central Mediterranean areas. For instance, Kazour et al., (2019) found that the 83.3\% of European anchovies analyzed had ingested microplastic in the Lebanese coast (Eastern Mediterranean Basin) and Renzi et al., 2019 found a 90\% in the Adriatic Sea (90\%) (Renzi et al., 2019a).

Previous studies in the Mediterranean Sea also showed high ingestion of microplastics for other species, such as Boops boops (57.8\%) and Mullus barbatus (18.8\%) in the Balearic Sea, and M. barbatus (33.3\%) and Trachinotus ovatus $(24.32 \%)$ in the Central Mediterranean (Bellas et al., 2016; Battaglia et al., 2016; Nadal et al., 2016). Some authors have also correlated microplastic ingestion with feeding strategies (Peters et al., 2017; Romeo et al., 2015). Accordingly, while in the pelagic realm the selection of particles can be related to the biometrics of the mouth (e.g. gape size, Bachiller and Irigoien, 2013) rather than the nutritional quality of the prey, in demersal environments the prey selection allows the rejection of certain prey species and debris (Deudero and Alomar, 2014). Despite both sardine and anchovy are able to use filter or particulate feeding (Costalago et al., 2015; Nikolioudakis et al., 2014; Bachiller et al. submitted), anchovy is a more particulate and selective feeder at adult stages or when food concentration is low (Compa et al., 2019, Costalago et al., 2014), while the feeding behaviour of sardine is preferentially filter-feeding (Bachiller and Irigoien, 2015; 
Nikolioudakis et al., 2014), showing a higher filtration rate (Collard et al. 2017; Nikolioudakis et al., 2014) and suggesting that the ingestion of anthropogenic particles is not selectively based (Garrido et al., 2007). However, our results show that the ingestion of microplastic frequency is similar in anchovy (60\%) and sardine (58\%). This might be explained by a higher filter-feeding mode by the small body-sized anchovy and especially in areas with high concentration of food (Costalago et al., 2014; Plounevez and Champalbert, 2000). However, the diet plasticity of both anchovy and sardine together with the random effect of the area found in the analyses might also suggest an opportunistic or accidental ingestion of microplastics, more related with the plastic abundance in the sea than with a certain particulate/selective feeding behaviour by certain fish species.

Accordingly, for sardine the latitude pattern is one of the main factors that explain the abundance of microplastics in gut contents, with lower probability to find microplastics in the northern areas. The sardine plasticscape confirms this trend and highlights the Gulf of Alicante as a riskier microplastic area. On the contrary, latitude was not a relevant factor to explain the anchovy ingested microplastics variability. For anchovy, despite the latitude not being a significant factor for ingested microplastic variability, the plasticscape highlighted that the Gulf of Lion and the Ebro Delta were the areas with a higher vulnerability for microplastic ingestion. These differences could be due to the different feeding behaviour of anchovy and sardine, and the different size distribution and occurrence of plastic fibers in individual areas. Future studies should look at this aspect in detail. It is interesting to mention that the three areas identified as areas with higher vulnerability for microplastic ingestion match with the identified "future climate refuges" for these species (i.e. areas in which these species will probably persist in under changes in environmental conditions) (Pennino et al., submitted). These results 
are especially relevant to elaborate spatially explicit management plan (e.g. MPA, etc.) for small pelagic species. Indeed, they show that the areas that consistently offer favorable habitats are also the ones with higher probability of microplastic ingestion and should be prioritize for conservation measures.

Neither the abundance of ingested microplastics of sardine, nor anchovy, were related with depth or longitude, in accordance with Compa et al. (2018) results. In addition, the random area effect selected for both species in the final model highlights some intrinsic geographical variability affecting the microplastic abundance ingested by fish. These variations between areas could be related to the different degree of exposure to human pressures such as anchoring allowance, maritime routes, legal protection regulations and waste discharges, as well as environmental factors (García et al., 2017). Different levels of organic matter from the river supply and vertical mixing is present in the sampled areas. These factors could entail the growth of phytoplankton and zooplankton, which attract high concentrations of small pelagic fish and also plastic debris coming from land (Bellido et al., 2008). However, due to the microplastics buoyancy and durability, these items can be transported through long distances and their ingestion in a given location is not strictly related to local sources but may result from additive sources (Nadal et al., 2016). Marine currents must be playing an important role in the spread of microplastics and areas characterized by convergence currents could be the ones that accumulate more debris that consequently are ingested by marine species. Further studies need to explore the relevance of oceanographic connectivity in microplastic dispersion, accumulation and ingestion.

In the case of anchovy, individuals with higher GSI index and smaller length showed more abundance of ingested microplastics. When the GSI is high, adult anchovy might be investing a high proportion of energy for reproduction, which requires higher 
quantities of food and therefore a higher feeding intensity that could increase the vulnerability of fish to microplastic ingestion (Somarakis et al., 2019). As already mentioned, smaller individuals of anchovy tend to show higher filter-feeding mode (Costalago et al., 2014; Plounevez and Champalbert, 2000), which could explain our results. This is the contrary in the case of sardine in the northwestern Mediterranean Sea, where filter feeding behaviour prevails as individuals are larger (Bachiller et al. submitted). Accordingly, in our study we did not find any relationship with sardine ingestion of plastic and fish size.

Of particular relevance in this study is the evidence for both species of a positive relationship between the abundance of parasite and the abundance of microplastics. As far as we know, this type of relation was only tested by Hernandez-Milian et al. (2019) in grey seals (Halichoerus grypus) and, although without a significant relationship, their results showed that microplastics tended to accumulate in areas where more parasites were aggregated. In our case both microplastics and parasites were found in the stomachs of sardine and anchovy along all the area without a specific trend for sardine. However, for anchovy the area with the highest frequency of ingested plastic and parasite was the Gulf of Lions. This might be related to the individuals distributed in more polluted areas having a higher probability of being infected by parasites and feeding on more microplastics. In addition, the highest number of ingested microplastics found in sardines with lower condition factors can suggest that (1) individuals with a better fit are less likely to ingest anthropogenic particles, or (2) that individuals showing higher vulnerability for plastic ingestion could subsequently derive on poorer body condition. Indeed, recent studies have showed negative effects related to the ingestion of microplastics by marine organisms, such as the reduction of growth and food consumption in the crab (Carcinus maenas) and the marine worm (Arenicola marina) (Watts et al., 2015; Wright et al., 
2013). Ferrer-Maza et al., (2016) showed that the current prevalence of smaller individuals in the northwestern Mediterranean anchovy stock might have several consequences for the health of the stock as a whole, because they have lower fecundity, lower lipid content and higher intensity of certain parasites. In the recent years, a reduction in the size of small pelagic species was also observed in the sampled study areas (Coll and Bellido 2018; Albo-Puigserver et al. in preparation) and consequently the high abundance of microplastics and parasites in these species could be an indirect effect.

Most of the microplastics found in gut contents of fish were classified as fibres that, according to several authors, are more abundant in the marine environment than fragments (Lusher et al., 2013; Rochman et al., 2015; Neves et al., 2015). The microplastic characterization procedure avoided the damaging of ingested plastics during the preservation in ethanol (Lusher et al., 2017) as well as the accidental counting of plastic pollution in samples (Rodriguez-Romeu et al., 2020). Plastic contents in fish stomachs, despite being characterized in a limited level of detail (i.e. visual microscope analysis), should be considered as conservative.

In conclusion, the ingested microplastics by anchovy and sardine observed in the Western Mediterranean, represent an initial evidence of contaminants transfer across the food web, given that these small pelagic species are also key prey for many other top predators, including commercial species (e.g. tuna; Gómez-Campos et al., 2011; Navarro et al., 2017). This is therefore a potential subsequent concern for human consumption. In fact, results suggest that most of the ingested particles might have been discharged from inland sources into the sea or from degradation of larger plastics from the fishing industry or other sources. The high prevalence and increasing production of microplastics in the ocean (Eriksen et al., 2014; Lebreton et al., 2019) make it necessary and urgent to further investigate microplastics distribution and species association, as well as microplastics- 
parasites aggregations and/or potential relationships, such as the one shown in this study. It is also essential to investigate the microplastics incidence related to other factors, such as prey and parasite prevalence, as well as the translocation of microplastics from the stomach to other organs and to potential consumers (Collard et al., 2017). The knowledge of these associations will be paramount in enabling the understanding of the microplastics issue.

\section{Acknowledgements}

This study was carried out within PELWEB (CTM2017-88939-R) and PELCAT (CAT 152CAT00013, TAIS ARP059/19/00005) projects. All gut content analyses under the microscope were carried out in the laboratory of AZTI (Pasaia, Spain), under the supervision of U. Cotano (Marine Ecosystem Functioning Area, AZTI, Basque Research and Technology Alliance (BRTA)). MEDITS data collection has been co-funded by the EU through the European Maritime and Fisheries Fund (EMFF) within the National Program of collection, management and use of data in the fisheries sector and support for scientific advice regarding the Common Fisheries Policy. The authors express their gratitude to all the people that work in the MEDITS surveys.

\section{References}

1. Albo-Puigserver, M., Navarro, J., Coll, M., Layman, C. A., Palomera, I., 2016. Trophic structure of pelagic species in the northwestern Mediterranean Sea. J. Sea Res, 117, 27-35.

2. Albo Puigserver, M., Bellido, J.M., Colmenero, A.I., Giraldez, A., Hidalgo, M., Grazia Pennino, M., Ramírez, J.G., Steenbeek, J., Torres, G., Coll, M., In preparation. Changes in life-history traits of small pelagic fish in the western Mediterranean Sea along a latitudinal gradient. Front. Mar. Sci.

3. Anastasopoulou, A., Mytilineou, C., Smith, C. J., Papadopoulou, K. N., 2013. Plastic debris ingested by deep-water fish of the Ionian Sea (Eastern Mediterranean). Deep-Sea Res. Pt. I., 74, 11-13. 
4. Avio, C. G., Gorbi, S., Regoli, F., 2015. Experimental development of a new protocol for extraction and characterization of microplastics in fish tissues: first observations in commercial species from Adriatic Sea. Mar. Environ. Res. 111, 18-26.

5. Bachiller, E., Irigoien, X., 2013. Allometric relations and consequences for feeding in small pelagic fish in the Bay of Biscay. ICES JMS 70, 232-243.

6. Bachiller, E., Irigoien, X., 2015. Trophodynamics and diet overlap of small pelagic fish species in the Bay of Biscay. Mar. Ecol. Prog. Ser. 534, 179-198.

7. Bachiller, E., Skaret, G., Nøttestad, L., Slotte, A., 2016. Feeding ecology of Northeast Atlantic mackerel, Norwegian spring-spawning herring and blue whiting in the Norwegian Sea. PloS one, 11(2), e0149238.

8. Baker, A.C. J., Bamford H.., 2009. Proc. International Research Workshop on the occurrence, effects and fate of microplastic marine debris, 9-11 September 2008. NOAA Technical Memorandum NOS-OR \& R 30.

9. Barboza, L. G. A., Lopes, C., Oliveira, P., Bessa, F., Otero, V., Henriques, B., ... Guilhermino, L., 2020. Microplastics in wild fish from North East Atlantic Ocean and its potential for causing neurotoxic effects, lipid oxidative damage, and human health risks associated with ingestion exposure, Sci. Total Environ., 717, 134625.

10. Battaglia, P., Pedà, C., Musolino, S., Esposito, V., Andaloro, F., Romeo, T., 2016. Diet and first documented data on plastic ingestion of Trachinotus ovatus L. 1758 (Pisces: Carangidae) from the Strait of Messina (central Mediterranean Sea). Ital. J. Zool. 83, 121-129. http://dx.doi.org/10.1080/11250003.2015.1114157.

11. Bellas, J., Martínez-Armental, J., Martínez-Cámara, A., Besada, V., MartínezGómez, C., 2016. Ingestion of microplastics by demersal fish from the Spanish Atlantic and Mediterranean coasts. Mar. Pollut. Bull. http://dx.doi.org/10.1016/j.marpolbul. 2016.06.026.

12. Bellido, J.M., Brown, Æ.A.M., Valavanis, V.D., Gira, Æ.A., Pierce, G.J., Iglesias, Æ.M., Palialexis, A., 2008. Identifying Essential Fish Habitat for Small Pelagic Species in Spanish Mediterranean Waters. pp. 171-184. In Essential Fish Habitat Mapping in the Mediterranean (pp. 171-184). Springer, Dordrecht. http://dx.doi.org/10.1007/s10750- 008-9481-2.

13. Bergmann, M., Gutow, L., Klages, M. (Eds.), 2015. Marine Anthropogenic Litter. Springer International Publishing, Heidelberg. B.

14. Bertrand, J. A., de Sola, L. G., Papaconstantinou, C., Relini, G., Souplet, A., 2002. The general specifications of the MEDITS surveys. Sci. Mar. 66(S2), 9-17.

15. Borme, D., Tirelli, V., Brandt, S. B., Umani, S. F., Arneri, E., 2009. Diet of Engraulis encrasicolus in the northern Adriatic Sea (Mediterranean): ontogenetic changes and feeding selectivity. Mar. Ecol. Prog. Ser. 392, 193-209.

16. Brosset, P., Fromentin, J-M., Ménard, F., Pernet, F., Bourdeix, J-H., Bigot, J.L., Van Beveren, E., Pérez Roda, M.A., Choy, S., Saraux, C., 2015. Measurement and analysis of small pelagic fish condition: A suitable method for rapid evaluation in the field. J. Exp. Mar. Bio. Ecol. 462, 90-97.

17. Casadevall, M., Torres, J., El Aoussimi, A., Carbonell, A., Delgado, E., SarràAlarcón, L., Bellido, J. M., 2016. Pollutants and parasites in bycatch teleosts from south eastern Spanish Mediterranean's fisheries: Concerns relating the foodstuff harnessing. Mar. Pollut. Bull., 104(1-2), 182-189.

18. Coll, M., Bellido, J.M., 2019. Evaluation of the population status and specific management alternatives for the small pelagic fish stocks in the Northwestern 
Mediterranean Sea (SPELMED) - Final Report SC NR. 02 - TENDER EASME/EMFF/2016/32 - SPELMED, 85.

19. Coll, M., Palomera, I., Tudela, S., Dowd, M., 2008. Food-web dynamics in the South Catalan Sea ecosystem (NW Mediterranean) for 1978-2003. Eco. Mod. 217(1-2), 95-116.

20. Collard, F., Gilbert, B., Compère, P., Eppe, G., Das, K., Jauniaux, T., Parmentier, E., 2017. Microplastics in livers of European anchovies (Engraulis encrasicolus, L.). Environ. Pollut., 229, 1000-1005.

21. Cole, M., Webb, H., Lindeque, P., Fileman, E., Halsband, C., Galloway, T. S., 2014. Isolation of microplastics in biota-rich samples and marine biota. Sci. Rep., 4(10.1038).

22. Compa, M., Ventero, A., Iglesias, M., Deudero, S., 2018. Ingestion of microplastics and natural fibres in Sardina pilchardus (Walbaum, 1792) and Engraulis encrasicolus (Linnaeus, 1758) along the Spanish Mediterranean coast. Marine pollution bulletin, 128, 89-96.

23. Costalago, D., Garrido, S., Palomera, I., 2015. Comparison of the feeding apparatus and diet of European sardines Sardina pilchardus of Atlantic and Mediterranean waters: ecological implications. J. Fish Biol., 86(4), 1348-1362.

24. Costalago, D., Palomera, I., Tirelli, V., 2014. Seasonal comparison of the diets of juvenile European anchovy Engraulis encrasicolus and sardine Sardina pilchardus in the Gulf of Lions. J. Sea Res., 89, 64-72.

25. Costalago, D., Navarro, J., Álvarez-Calleja, I., Palomera, I., 2012. Ontogenetic and seasonal changes in the feeding habits and trophic levels of two small pelagic fish species. Mar. Ecol. Prog. Ser. 460, 169-181.

26. Cózar A, Sanz-Martín M, Martí E, González-Gordillo JI, Ubeda B, Gálvez JÁ, et al., 2015. Plastic Accumulation in the Mediterranean Sea. PLoS ONE 10(4): $\mathrm{e} 0121762$.

27. de Haan, W. P., Sanchez-Vidal, A., Canals, M., Party, N. S. S., 2019. Floating microplastics and aggregate formation in the Western Mediterranean Sea. Mar. Pollut. Bull., 140, 523-535.

28. Deudero, S., Alomar, C., 2015. Mediterranean marine biodiversity under threat: reviewing influence of marine litter on species. Mar. Pollut. Bul. 98(1-2), 58-68.

29. Eriksen, M., Lebreton, L.C.M., Carson, H.S., Thiel, M., Moore, C.J., Borerro, J.C., Galgani, F., Ryan, P.G., Reisser, J., 2014. Plastic pollution in the world's oceans: more than 5 trillion plastic pieces weighing over 250,000 tons afloat at sea. PLoS One 9, e111913. http://dx.doi.org/10.1371/journal.pone.0111913.

30. European Parliament, Council of the European Union Directive 2008/56/EC of the European Parliament and of the Council Off. J. Eur. Union, 164 (2008), pp. 19-40.

31. FAO, 2018. The state of Mediterranean and Black Sea fisheries 2018. General Fisheries Commission for the Mediterranean, Rome.

32. Ferrer-Maza, D., Lloret, J., Muñoz, M., Faliex, E., Vila, S., Sasal, P., 2016. Links between parasitism, energy reserves and fecundity of European anchovy, Engraulis encrasicolus, in the northwestern Mediterranean Sea. Conserv. Physiol., 4, doi:10.1093/conphys/cov069

33. Filgueiras, A.V., Gago, J., Campillo, J.A., Leon, V.M., 2019. Microplastic distribution in surface sediments along the Spanish Mediterranean continental shelf. Environ. Sci. Pollut. Res., 26, 21264-21273. https://doi.org/10.1007/s11356-019-05341-5 
34. García-Rivera, S., Sánchez Lizaso, J.L., Bellido, J.M., 2015. A quantitative and qualitative assessment of the discard ban in European Mediterranean waters. Mari. Pol., 53, 149-158.

35. García-Rivera, S., Sánchez Lizaso, J.L., Bellido, J.M., 2018. Spatial and temporal trends of marine litter in the Spanish Mediterranean Seafloor. Mar. Pollut. Bull., 137, 252-261. https://doi.org/10.1016/j.marpolbul.2018.09.051

36. Garrido, S., Marçalo, A., Zwolinski, J., Van Der Lingen, C.D., 2007. Laboratory Investigations on the Effect of Prey Size and Concentration on the Feeding Behaviour of Sardina pilchardus. Mar. Ecol. Prog. Ser. 330, 189-199.

37. Gelman, A., 2008. Scaling regression inputs by dividing by two standard deviations. Stat. Med. 27(15), 2865-2873.

38. Giannoulaki, M., Iglesias, M., Tugores, M.P., Bonanno, A., Patti, B., De Felice, A., Leonori, I., Bigot, J-L., Tičina, V., Pyrounaki, M., 2013. Characterizing the potential habitat of European anchovy Engraulis encrasicolus in the Mediterranean Sea, at different life stages. Fish. Oceanogr. 22, 69-89.

39. Giannoulaki, M., Pyrounaki, M.M., Liorzou, B., Leonori, I., Valavanis, V.D., Tsagarakis, K., Bigot, J.L., Roos, D., De Felice, A., Campanella, F., 2011. Habitat suitability modelling for sardine juveniles (Sardina pilchardus) in the Mediterranean Sea. Fish. Oceanogr. 20, 367-382.

40. Gómez-Campos, E., Borrell, A., Cardona, L., Forcada, J., Aguilar, A., 2011. Overfishing of small pelagic fishes increases trophic overlap between immature and mature striped dolphins in the Mediterranean Sea. PloS one, 6(9), e24554.

41. Hernandez-Milian, G., Lusher, A., MacGabban, S., Rogan, E., 2019. Microplastics in grey seal (Halichoerus grypus) intestines: Are they associated with parasite aggregations?. Mar. Pollut. Bul. 146, 349-354.

42. Hereford, J., Hansen, T. F., Houle, D., 2004. Comparing strengths of directional selection: how strong is strong?. Evolution, 58(10), 2133-2143.

43. Hyslop, E. J., 1980. Stomach contents analysis-a review of methods and their application. J. Fish Biol. 17(4), 411-429.

44. Ioakeimidis, C., Zeri, C., Kaberi, H., Galatchi, M., Antoniadis, K., Streftaris, N., Galgani, F., Papathanassiou, E., Papatheodorou, G., 2014. A comparative study of marine litter on the seafloor of coastal areas in the Eastern Mediterranean and Black Seas. Mar. Pollut. Bull., 89.1-2 (2014): 296-304.

45. Jeong, C. B., Kang, H. M., Lee, M. C., Kim, D. H., Han, J., Hwang, D. S., ... Lee, J. S., 2017. Adverse effects of microplastics and oxidative stress-induced MAPK/Nrf2 pathway-mediated defense mechanisms in the marine copepod Paracyclopina nana. Sci. rep., 7(1), 1-11.

46. Katsanevakis, S., Katsarou, A., 2004. Influences on the distribution of. marine debris on the seafloor of shallow coastal areas in Greece (Eastern Mediterranean). Water, Air, Soil Pollut., 159(1), 325-337.

47. Kazour, M., Jemaa, S., Issa, C., Khalaf, G., Amara, R., 2019. Microplastics pollution along the Lebanese coast (Eastern Mediterranean Basin): Occurrence in surface water, sediments and biota samples. Sci.. Total Environ., 696, 133933.

48. Le Cren, E.D., 1951. The Length-Weight Relationship and Seasonal Cycle in Gonad Weight and Condition in the Perch (Perca fluviatilis). J. Anim. Ecol. 20, 201.

49. Lebreton, L., Egger, M., Slat, B., 2019. A global mass budget for positively buoyant macroplastic debris in the ocean. Scientific reports, 9(1), 1-10. 
50. Lindgren, F., Rue, H., Lindström, J., 2011. An explicit link between Gaussian fields and Gaussian Markov random fields: the stochastic partial differential equation approach. J. R. Stat. Soc. Series B. 73(4), 423-498.

51. Lusher, A.L., McHugh, M., Thompson, R.C., 2013. Occurrence of microplastics in the gastrointestinal tract of pelagic and demersal fish from the English Channel. Mar. Pollut. Bull. 67, 94-99.

52. Lusher, A.L., Welden, N.A., Sobral, P., Cole, M., 2017. Sampling, isolating and identifying microplastics ingested by fish and invertebrates. Anal. Methods 0, 115. http://dx. doi.org/10.1039/C6AY02415G.

53. Mellon-Duval, C., Harmelin-Vivien, M., Métral, L., Loizeau, V., Mortreux, S., Roos, D., Fromentin, J. M., 2017. Trophic ecology of the European hake in the Gulf of Lions, northwestern Mediterranean Sea. Sci. Mar. 81(1), 7-18.

54. Muñoz, F., Pennino, M. G., Conesa, D., López-Quílez, A., Bellido, J. M., 2013. Estimation and prediction of the spatial occurrence of fish species using Bayesian latent Gaussian models. Stoch. Env. Res. Risk A. 27(5), 1171-1180.

55. Nadal, M. A., Alomar, C., Deudero, S., 2016. High levels of microplastic ingestion by the semipelagic fish bogue Boops boops (L.) around the Balearic Islands. Environ. Pollut., 214, 517-523. doi:10.1016/j.envpol.2016.04.054

56. Navarro, J., Grémillet, D., Ramirez, F. J., Afán, I., Bouten, W., Forero, M. G., 2017. Shifting individual habitat specialization of a successful predator living in anthropogenic landscapes. Mar. Ecol. Prog. Ser. 578, 243-251.

57. Navarro, J., Louzao, M., Igual, J. M., Oro, D., Delgado, A., Arcos, J. M., ... Forero, M. G., 2009. Seasonal changes in the diet of a critically endangered seabird and the importance of trawling discards. Mar. Biol., 156(12), 2571-2578.

58. Neves, D., Sobral, P., Ferreira, J. L., Pereira, T., 2015. Ingestion of microplastics by commercial fish off the Portuguese coast. Mar. Pollut. Bul. 101(1), 119-126.

59. Nikolioudakis, N., Isari, S., Somarakis, S., 2014. Trophodynamics of anchovy in a non-upwelling system: direct comparison with sardine. Mar. Ecol. Prog. Ser. 500, 215-229.

60. Palomera, I., Olivar, M. P., Salat, J., Sabatés, A., Coll, M., García, A., MoralesNin, B., 2007. Small pelagic fish in the NW Mediterranean Sea: an ecological review. Progr. Oceanogr. 74(2-3), 377-396.

61. Palomera, I., Tejeiro, B., Alemany, F., 2003. Size at first maturity of the NW Mediterranean anchovy. GFCM-SAC Sub-Committee Stock Assess WG Small Pelagic Species March 2003, Tangiers.

62. Pennino, M. G., Coll, M., Albo-Puigserver, M., Fernández-Corredor, E., Steenbeek, J., Bellido. J.M.Current and future influence of environmental factors on small pelagic fish distributions in the Northwestern Mediterranean Sea. Front. Mar. Sci. Submitted.

63. Plounevez, S., Champalbert, G., 2000. Diet, feeding behaviour and trophic activity of the anchovy (Engraulis encrasicolus L.) in the Gulf of Lions (Mediterranean Sea). Oceanologica Acta, 23(2), 175-192.

64. Ramirez-Llodra, E., De Mol, B., Company, J.B., Coll, M., Sarda, F., 2013. Effects of natural and anthropogenic processes in the distribution of marine litter in the deep Mediterranean Sea. Progr. Oceanogr. 118, 273-287.

65. Renzi, M., Specchiulli, A., Blašković, A., Manzo, C., Mancinelli, G., Cilenti, L., 2019a. Marine litter in stomach content of small pelagic fishes from the Adriatic Sea: sardines (Sardina pilchardus) and anchovies (Engraulis encrasicolus). Environ. Sci. Pollut. Res. 26, 2771-2781. https://doi.org/10.1007/s11356-0183762-8. 
66. Rochman, C.M., Kurobe, T., Flores, I., Teh, S.J., 2014. Early warning signs of endocrine disruption in adult fish from the ingestion of polyethylene with and without sorbed chemical pollutants from the marine environment. Sci. Total Environ. 493, 656-661. http://dx.doi.org/10.1016/j.scitotenv.2014.06.051.

67. Romeo, T., Pietro, B., Pedà, C., Consoli, P., Andaloro, F., Fossi, M. C., 2015. First evidence of presence of plastic debris in stomach of large pelagic fish in the Mediterranean Sea. Mar. Pollut. Bul. 95(1), 358-361.

68. Roos, M., Held, L., 2011. Sensitivity analysis in Bayesian generalized linear mixed models for binary data. Bayesian Anal. 6(2), 259-278.

69. Rodríguez-Romeu, O., Constenla, M., Carrassón, M.., Campoy-Quiles, M., SolerMembrives, A. S., 2020. Are antropogenic fibres a real problema for the red mullets (Mullus barbatus) from the NW Mediterranean? Science of the Total Environment 733, 139336.

70. Rue, H., Martino, S., Chopin, N., 2009. Approximate Bayesian inference for latent Gaussian models by using integrated nested Laplace approximations. J. R. Stat. Soc. Series B. 71(2), 319-392.

71. Silva, A., Santos, M. B., Caneco, B., Pestana, G., Porteiro, C., Carrera, P., and Stratoudakis, Y. 2006. Temporal and geographic variability of sardine maturity at length in the northeastern Atlantic and the western Mediterranean. ICES J. Mar. Sci., 63, 663-676.

72. Smith, M., Love D.C., Rochman, C.M., Neff, R.A., 2018. Microplastics in Seafood and the Implications for Human Health. Curr. Environ. Health. Rep. 5(3), 375-386. doi:10.1007/s40572-018-0206-z

73. Somarakis, S., Tsoukali, S., Giannoulaki, M., Schismenou, E., Nikolioudakis, N., 2019. Spawning stock, egg production and larval survival in relation to small pelagic fish recruitment. Mar. Ecol. Prog. Ser., 617, 113-136. https://doi.org/10.3354/meps12642

74. Spedicato, M. T., Zupa, W., Carbonara, P., Fiorentino, F., Follesa, M. C., Galgani, F. et al., 2020. Spatial distribution of marine macro-litter on the seafloor in the northern Mediterranean Sea: the MEDITS initiative. Sci. Mar. 83(S1), 257-270.

75. St. John Glew, K., Graham, L. J., McGill, R. A., Trueman, C. N., 2019. Spatial models of carbon, nitrogen and sulphur stable isotope distributions (isoscapes) across a shelf sea: An INLA approach. Methods Ecol. Evol. 10(4), 518-531.

76. Suaria, G., Musso, M., Achtypi, A., Bassotto, D., Aliani, S., 2020 Textile Fibres in Mediterranean Surface Waters: Abundance and Composition. In International Conference on Microplastic Pollution in the Mediterranean Sea (pp. 62-66). Springer, Cham.

77. Teuten, E. L., Saquing, J. M., Knappe, D. R., Barlaz, M. A., Jonsson, S., Björn, A., ... Ochi, D., 2009. Transport and release of chemicals from plastics to the environment and to wildlife. Philos. Trans. R. Soc. Lond. B. Biol. Sci., 364(1526), 2027-2045.

78. Watts, A.J.R., Urbina, M.A., Corr, S., Lewis, C., Galloway, T.S., 2015. Ingestion of plastic microfibers by the crab Carcinus maenas and its effect on food consumption and en- ergy balance. Environ. Sci. Technol. 49, 14597-14604. http://dx.doi.org/10.1021/ acs.est.5b04026.

79. Watanabe, S., 2010. Asymptotic equivalence of Bayes cross validation and widely applicable information criterion in singular learning theory. J. Mach. Learn. Res. 11, 3571-3594. 
80. Welden, N. A.C, Cowie, P. R., 2016. Long-term microplastic retention causes reduced body condition in the langoustine, Nephrops norvegicus. Environ. Pollut., 218, 895-900.

81. Woodall, L. C., Sanchez-Vidal, A., Canals, M., 2014. The deep sea is a major sink for microplastic debris. R. Soc. Open Sci., 1:140317.

82. Wright, S.L., Rowe, D., Thompson, R.C., Galloway, T.S., 2013. Microplastic ingestion decreases energy reserves in marine worms. Curr. Biol. 23. http://dx.doi.org/10. 1016/j.cub.2013.10.068.

83. Yu, P., Liu, Z., Wu, D., Chen, M., Lv, W., Zhao, Y., 2018. Accumulation of polystyrene microplastics in juvenile Eriocheir sinensis and oxidative stress effects in the liver. Aquat. Toxicol., 200, 28-36.

84. Zuur, A.F., Ieno, E.N., Elphick, C.S., 2010. A protocol for data exploration to avoid common statistical problems. Methods Ecol. Evol. 1, 3-14. http://dx.doi.org/10. 1111/j.2041-210X.2009.00001.x. 